DOI: $10.26418 /$ positron.v10i2.43310

\title{
Kajian Nilai Percepatan Puncak di Daerah Kulon Progo Utara, Yogyakarta, Indonesia, Berbasis Peta Gempa Nasional 2017 dan Pengukuran Mikrotremor
}

\author{
Eddy Hartantyo ${ }^{\mathrm{a}^{*}}$, Novia Nurul Khayati ${ }^{\mathrm{b}}$, Rusnianti Nur ${ }^{\mathrm{b}}$, Skolastika Novita $\mathrm{W}^{\mathrm{b}}$ \\ aKBK Geosains, Lab Geofisika, Dep Fisika, FMIPA, UGM, Sekip Utara Yogyakarta, 55281, Indonesia \\ bProgram S2 Fisika, FMIPA, UGM, Sekip Utara Yogyakarta, 55281, Indonesia \\ *Email : hartantyo@ugm.ac.id \\ (Diterima 24 November 2020; Disetujui 20 Desember 2020; Dipublikasikan 29 Desember 2020)
}

\begin{abstract}
Abstrak
Daerah Kulon Progo bagian utara memiliki morfologi perbukitan batuan lapuk dengan banyak kejadian longsor. Terdapat 16 titik wisata di daerah ini, sehingga sangat penting untuk dilakukan kajian resiko bencana longsor. Salah satu data cukup penting dalam perhitungan empiris adalah kajian nilai peak ground acceleration (PGA)/nilai percepatan puncak lokal di permukaan. PGA dihitung menggunakan kombinasi pengukuran mikroseismik dan peta PGA di batuan dasar untuk berbagai skenario deterministik maupun probabilistik. Sebanyak 78 data mikroseismik yang tersebar dengan pusat Desa Gerbosari dan sekitarnya diukur menggunakan Lennartz $1 \mathrm{~Hz}$ dengan sampling perekaman $100 \mathrm{~Hz}$ selama masing-masing 40-45 menit. Data diproses menggunakan modul horizontal to vertical spectral ratio (HVSR) di Geopsy. Hasil yang diperoleh menunjukkan bahwa 55\% data merupakan clearpeak, 23\% clearpeak dengan noise rendah, dan $10 \%$ noise sedang. Amplitudo amplifikasi diperoleh hingga 5 kali, terutama di sisi tenggara dan barat Desa Gerbosari. Pada daerah dengan amplifikasi tinggi tersebut diperoleh nilai PGA untuk skenario P01, P07 dan P10 masing-masing sebesar 0,8 g, 3,8 g dan minimal 5 g. Daerah dengan nilai PGA dan amplifikasi tinggi bersesuaian dengan lokasi-lokasi yang dilaporkan terjadi longsor yang dipicu oleh jenuhnya air, kemiringan lereng, dan amplifikasi goncangan, terutama yang berdekatan dengan jalan raya.
\end{abstract}

Kata kunci: HVSR, Kulon Progo, longsor, PGA

\section{Latar Belakang}

Fenomena pergeseran tanah dengan luasan yang cukup besar, sering disebut sebagai tanah longsor, merupakan salah satu jenis bencana alam yang sering terjadi di Indonesia. Bencana ini umumnya terjadi pada daerah dengan litologi batuan yang terlapukkan [1] dengan kemiringan cukup besar dan curah hujan yang tinggi [2]. Lapisan batuan yang terlapukkan tersebut umumnya berada dekat dengan permukaan tanah dengan kedalaman beberapa meter hingga puluhan meter. Apabila gaya gesek antar butir pada material lapukan tersebut lebih kecil daripada beban gravitasinya (umumnya akibat penambahan air dalam pori-porinya), potensi terlepasnya ikatan antar butir menjadi lebih besar [3]. Jika kondisi ini terjadi dalam daerah yang luas, luncuran tanah longsor lepas dapat mengancam infrastruktur yang berada di bawahnya [4].

Daerah Kecamatan Samigaluh Kabupaten Kulonprogo memiliki banyak wisata alam yang menarik. Terdapat 16 wisata alam terdekat dengan daerah penelitian diperkirakan memiliki potensi bahaya tanah longsor yang tinggi. 16 wisata tersebut terbagi dalam empat kawasan, yaitu: Kawasan A (Kebun The nglinggo, Puncak Widosari, Bukit ISIS, Kedai Telo, Bukit Ngisis Nglinggo, Grojogan Watu Jonggol), Kawasan B (Air Terjun Sidoharjo, Curug Siluwok, Watu Tekek, Wisata Air Terjun Watu Jengger), Kawasan C (Agriwisata Krisan Gerbosari, Kedung Sowo, Gardu Pandang Tanggulangsi), dan Kawasan D (Puncak Kleco, Desa Wisata Tinalah, Goa Sriti).

Salah satu lokasi yang terindikasi adanya pergerakan di permukaan tanah terletak di sisi kiri dan kanan jalan jalur utama wisata daerah perbukitan Kulon Progo bagian utara. Potensi longsor terbesar berada di Kecamatan Samigaluh, terutama Desa Ngargosari, Gerbosari dan Banjarsari, karena kondisi geologi permukaan yang sangat lapuk dan memiliki topografi curam. Kondisi ini menjadi salah satu penyebab mudahnya beberapa titik pada jalur wisata yang melewati kecamatan ini menjadi rawan longsor.

Pada akhir November 2016, terjadi longsor yang menerjang tiga Kecamatan Kalibawang, Girimulyo, dan Samigaluh [5]. Lokasi terparah 
terdapat pada Dusun Borosuci, Desa Banjarasri, Kecamatan Kalibawang. Longsoran menutup jalan penghubung alternatif antara ulonprogo dan Purworejo. Di Kecamatan Samigaluh, longsor menutup jalur utama pariwisata ke beberapa obyek di lokasi di sebelah baratnya. Kejadian longsor ini dilaporkan setiap tahun terutama saat musim hujan tiba.

Disamping analisis terhadap kedalaman bidang gelincir, arah gelincir dan perkiraan volume material yang sangat penting untuk memperkirakan lebar daerah cakupan longsor dan kajian perbaikan tanah [6], kajian terhadap nilai peak ground acceleration (PGA)/percepatan puncak sangat diperlukan. Nilai PGA yang tinggi menjadi tolok ukur tingkat bahaya akibat gempa bumi yang terjadi pada suatu wilayah.

Nilai PGA diperlukan untuk perhitungan kajian pseudostatik rayapan, baik dengan pohon logika maupun deterministik. Dalam tulisan ini, nilai PGA di permukaan diperoleh dari gabungan rasio horisontal to vertical spectral ratio (HVSR) dari pengukuran mikrotremor $[7,8]$ dan peta nilai PGA di batuan dasar untuk berbegai skenario deterministik maupun probabilistik [9].

Berdasarkan kajian dari Pusat Gempa Nasional 2017 (PGN2017), telah dipetakan nilai PGA berdasar kombinasi deterministic seismic hazard analysis (DSHA) dan probabilistic seismic hazard analysis (PSHA) untuk wilayah Indonesia yang berlaku di batuan dasar $\left(\mathrm{S}_{\mathrm{B}}\right)$. Namun, kajian lokal masih diperlukan untuk melihat distribusi PGA [10], mengingat penguatan/amplifikasi terhadap nilai PGA juga bisa terjadi akibat keberadaan lapisan sedimen dibagian atas. Dalam tulisan ini, nilai PGA lokal ditentukan menggunakan nilai amplitudo amplifikasi nilai HVSR yang dikombinasi dengan PGA dari PGN2017. Nilai PGA dari PGN adalah nilai di batuan dasar, sedangkan nilai HVSR adalah penguatan/amplifikasi dari permukaan terhadap batuan dasar [11]. Dalam tulisan ini, nilai PGA batuan dasar diperoleh dari data sekunder, sedangkan nilai ampliifkasi dari HVSR dan nilai PGA lokal di permukaan yang dihasilkan diperoleh dari data primer.

\section{Metodologi}

Data 78 titik pengukuran mikroseismik diambil selama 16 hari pada bulan Agustus 2020 di area penelitian yang tersebar di bagian utara dan selatan jalur utama (Gambar 1). Lokasi pengambilan data dipilih berdasarkan distribusi penyebaran, tingkat noise aktif, dan kesampaian daerahnya. Kesampaian daerah adalah lokasi yang relatif mudah dicapai dengan kendaraan motor roda dua. Instrumen seismometer menggunakan Lennartz 1 $\mathrm{Hz}$ dikombinasikan dengan data logger dari data acquisition (DAQ) yang direkam menggunakan laptop. Waktu pengambilan data disetiap titik adalah 40-45 menit. Sebagai landasan, digunakan konblok cor semen sebagai alas seismometer agar kopling dengan tanah cukup baik. Perekaman dilakukan menggunakan frekuensi sampling $100 \mathrm{~Hz}$ dengan target frekuensi $0-20 \mathrm{~Hz}$.

Pemrosesan data dilakukan secara standar menggunakan metode HVSR dalam software Geopsy. Window sampling dan jumlah window sebanyak 40 window dan proses perhitungan kawasan frekuensi menggunakan fast Fourier transform (FFT) dengan band pass filter (BPF) $20 \mathrm{~Hz}$. Penghalusan data dalam kawasan frekuensi dilakukan menggunakan Konno Ohmaci filter. Data diproses secara sekuensial sehingga diperoleh kurva HVSR untuk setiap lapangan. Contoh data hasil proses ditunjukkan pada Gambar 2 .

Terdapat 5 kondisi kriteria dalam penelitian ini, yaitu clearpeak ( $c p)$, noise rendah (n1), noise sedang (n2), 2 puncak clearpeak (2cp), dan data sangat noisy (tidak dipakai). Penentuan kondisi

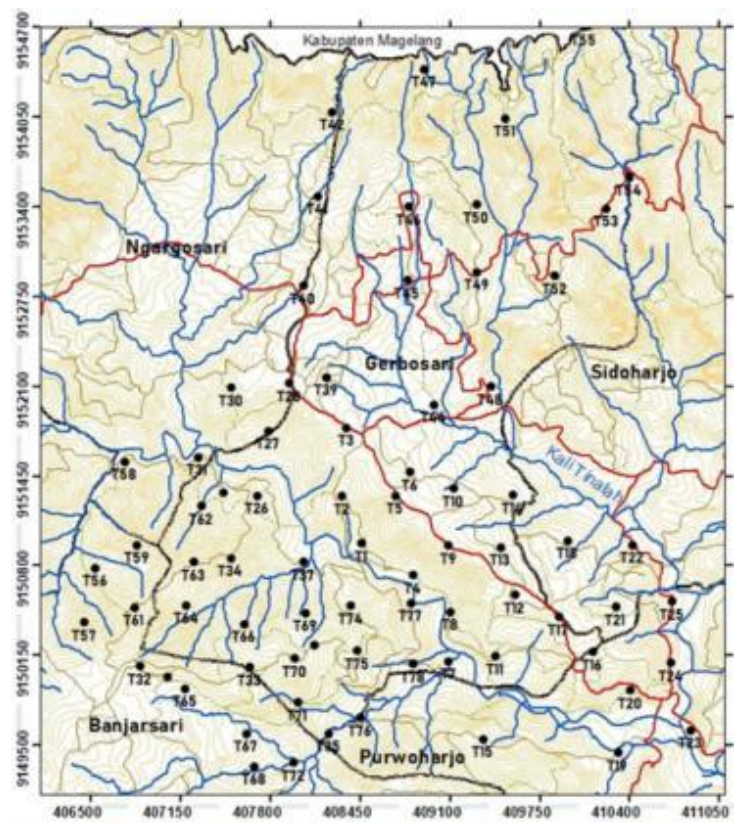

Gambar 1. Persebaran titik pengukuran mikroseismik (dot hitam). Garis merah adalah jalan utama yang menghubungkan Yogyakarta (timur), Kabupaten Purworejo (barat) dan Kabupaten Magelang (utara). Garis biru adalah sungai dan kontur kuning menunjukkan topografi. 
tersebut dan pembagian kriterianya dilakukan secara visual. Dalam prosesnya, semua data kecuali kurva HVSR yang sangat noisy, digunakan dalam kajian ini. Khusus untuk data $2 c p$, dipilih nilai amplifikasi yang lebih kuat dari dua frekuensi puncaknya.

Amplitudo yang didapatkan dalam setiap data menunjukkan penguatan spektral komponen horisontal yang terjadi di permukaan dibandingkan dengan di batuan dasar $\left(\mathrm{S}_{\mathrm{B}}\right)$. Dengan asumsi bahwa komponen horisontal akselerasi dari setiap even gempa adalah nilai dari komponen horisontalnya, maka dapat metode HVSR dapat dikaitkan dengan PGA. Nilai PGA umumnya dihitung di $S_{B}$ untuk berbagai skenario, baik deterministik maupun probabilistik. Nilai PGA tersebut diperoleh dari hasil kerja Pusat Gempa Nasional tahun 2017.

\section{Hasil dan Pembahasan}

Berdasar klasifikasi kondisi kategori yang dihasilkan, diperoleh sebanyak 6 titik data (8\%) yang sangat noisy dan datanya tidak digunakan (lihat Tabel 1). Akan tetapi, terdapat 43 data (55\%) berupa clear peak, 18 data noise rendah (23\%), dan 8 data noise sedang (10\%), sehingga data yang dihasilkan dalam penelitian ini cukup valid.
Tabel 1. Klasifikasi kondisi kriteria data HVSR. Total sebanyak 78 data.

\begin{tabular}{lcc}
\hline Kondisi & Jumlah & Persentase \\
\hline$c p$ & 43 & $55 \%$ \\
$n 1$ & 18 & $23 \%$ \\
$n 2$ & 8 & $10 \%$ \\
$2 c p$ & 3 & $4 \%$ \\
NotUsed & 6 & $8 \%$
\end{tabular}

Hasil plot nilai amplifikasi HVSR ditunjukkan pada Gambar 3. Pada plot ini, kondisi kriteria juga dituliskan untuk memberikan kemudahan dalam analisis. Terdapat dua titik data yang membentuk pola bulls-eye, yaitu titik T27 dan T15. Berdasar pola kontur yang diperoleh, nilai amplifikasi sebesar 7 ke atas nampak tertarik oleh pola bullseye ini. Namun, mengingat kedua titik ini mendapatkan kriteria kondisi $c p$, maka data yang ditunjukkan cukup valid. Secara umum, kecuali dua bulls-eye tadi, diperoleh nilai ampliifkasi maksimum 6 dengan lokasi disekitar bulls-eye, dan daerak utara penelitian (perbatasan dengan Kabupaten Magelang).

Desa Gerbosari yang memiliki riwayat longsor cukup banyak memiliki nilai amplifikasi yang rendah di bagian utara dan selatan. Namun, pada
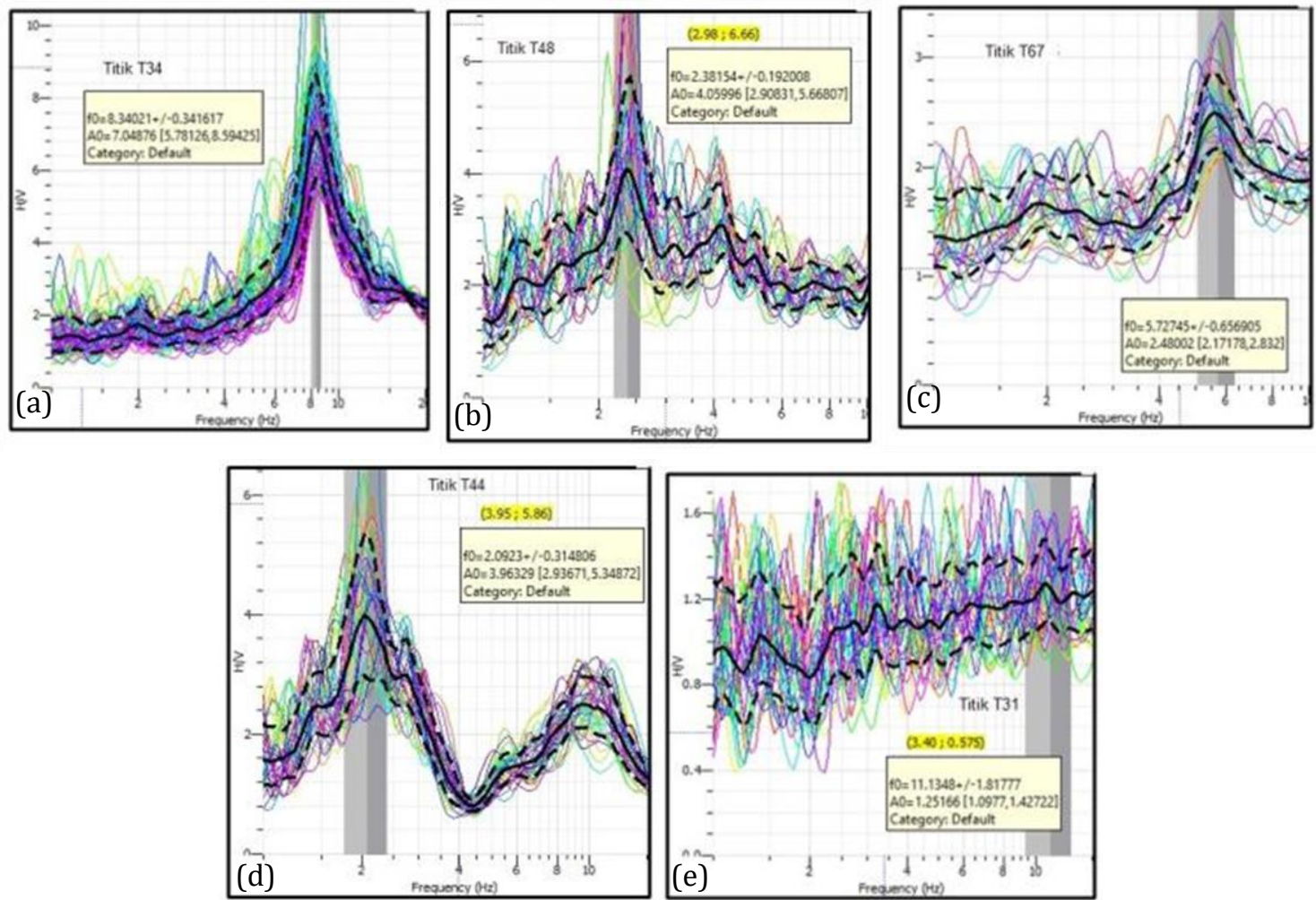

Gambar 2. Contoh data HVSR dalam kelompok kriteria kondisinya. (a) $c p$, (b) $n 1$, (c) $n 2$, (d) $2 c p$, dan (e) sangat noisy tidak dipakai dalam kajian ini. 


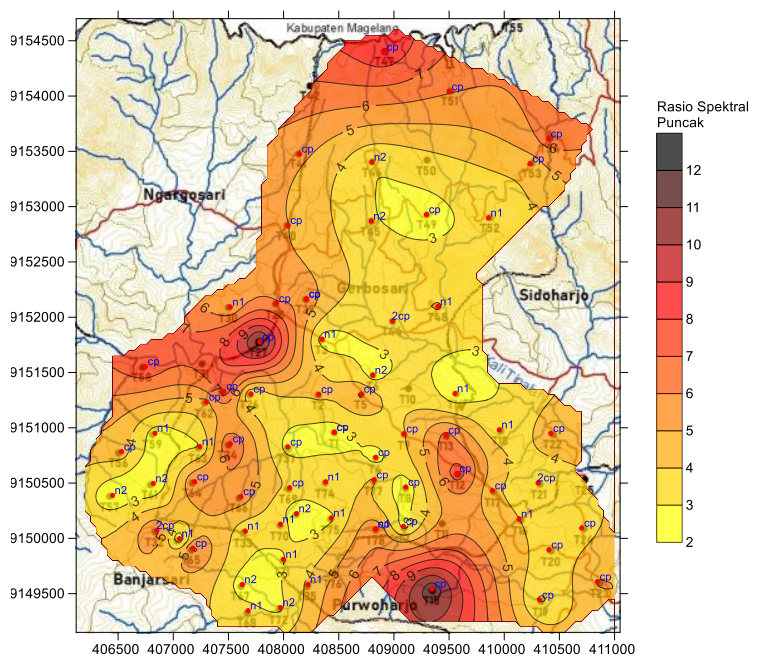

Gambar 3. Persebaran titik pengukuran mikroseismik (dot merah). Garis merah adalah jalan utama yang menghubungkan Yogyakarta (timur), kabupaten Purworejo (barat) dan kabupaten Magelang (utara). Garis biru adalah sungai dan kontur kuning menunjukkan topografi.

sisi barat dan tenggara, amplifikasi terdindikasi cukup tinggi. Dilihat dari lokasinya, tingginya amplifikasi ini relatif bersesuaian dengan posisi seringnya terjadi longsor di Gerbosari, yaitu pada wilayah tenggara, tepat berada pada area dengan amplifikasi $>4$.

Pada keempat desa disekitarnya, distribusi data hanya sebagian saja. Desa Sukoharjo di sebelah timur memiliki amplifikasi yang tidak terlalu besar, khususnya di Desa Sukoharjo sisi barat. Desa Purwoharjo di sisi selatan yang juga berbatasan dengan Gerbosari, memiliki amplifikasi yang sedang. Untuk dua desa lainnya, yaitu Ngargosari dan Banjarsari, menurut laporan juga sering terjadi bencana longsor. Terlihat bahwa nilai amplifikasi di sebelah utara Desa Banjarsari cukup tinggi, sedangkan di sisi timur Desa Ngargosari juga bernilai tinggi. Secara umum, dapat dikatakan bahwa semua area tertutupi oleh lapukan, terlihat dari nilai amplifikasi yang ada lebih dari 1.

Berdasar data dari Peta Sumber dan Bahaya Gempa, nilai PGA di batuan dasar $\left(\mathrm{S}_{\mathrm{B}}\right)$ untuk lokasi penelitian dapat ditentukan. Mengingat skala yang digunakan dalam peta tersebut sangat kecil, maka untuk seluruh lokasi penelitian ini hanya diperoleh satu nilai. Nilai yang diambil adalah nilai tengah dari skala kontur warna dalam peta tersebut. Tabel lengkap yang berisi nilai PGA $\left(\mathrm{S}_{\mathrm{B}}\right)$, yang diturunkan dari skenario baik deterministik maupun probabilistik, ditunjukkan pada Tabel 2

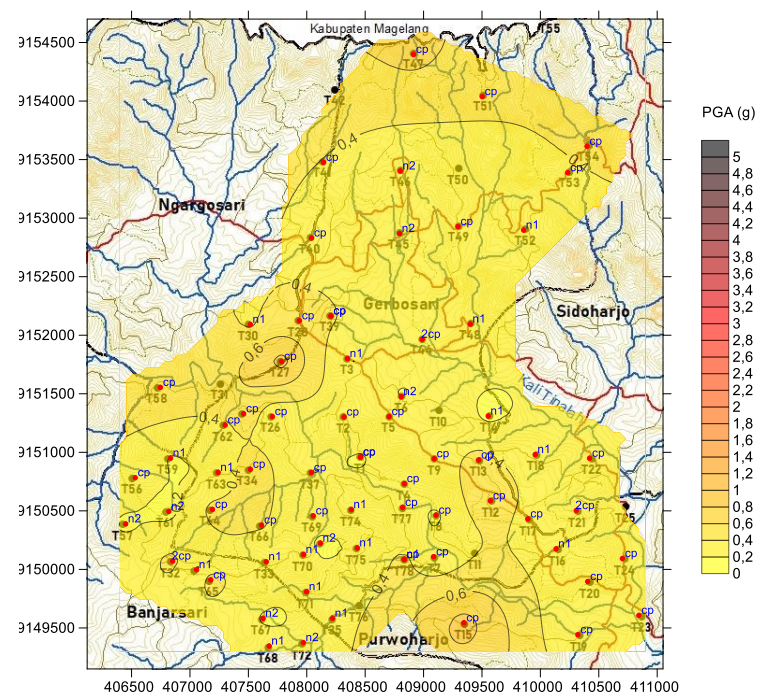

Gambar 4. Nilai PGA untuk skenario P01. Nilai maksimum PGA di permukaan tanah sekitar $0.8 \mathrm{~g}$ yang diperoleh pada puncak nilai maksimum sesuai Gambar 3.

Nilai PGA di batuan dasar $S_{B}$ terkecil di lokasi penelitian diperoleh sebesar 0.075 g untuk P01, yaitu perhitungan dengan probabilitas terlampaui lebih besar dari 20\% dalam 10 tahun. Nilai ini relatif kecil dibandingkan dengan kejadian gempa bumi Yogyakarta 5.8 Mw pada Mei 2006. Di lokasi ini, diperoleh nilai PGA mencapai $0.36 \mathrm{~g}$ di batuan $\mathrm{S}_{\mathrm{B}}[9]$.

Nilai PGA yang cukup besar berada pada $0.8 \mathrm{~g}$, yaitu untuk skenario P10 yaitu perhitungan probabilitas terlampaui lebih dari $1 \%$ dalam 100 tahun. Namun, mengingat kelengkapan data gempa berada pada kisaran 50 tahun, maka skenario P01 memiliki nilai yang paling signifikan.

Sesuai dengan pemodelan, sebagian besar frekuensi resonansi mode 1 untuk bangunan adalah $1 \mathrm{~Hz}[12,13]$, maka nilai PGA yang didapatkan untuk skenario P07, yaitu spektrum respon 1sec dengan koefisien redaman sebesar $5 \%$ di batuan dasar selama 75 tahun adalah $0.35 \mathrm{~g}$. Nilai ini relatif lebih kecil dibandingkan dengan skenario tertinggi yaitu sebesar 0,8 g.

Pada tulisan ini, hanya skenario P01, P07 dan P10 yang disajikan. Skenario untuk P01 disajikan pada Gambar 4. Nilai tertinggi untuk skenario ini adalah sebesar $0,6 \mathrm{~g}$.

Skenario P01 memberikan nilai PGA yang cukup kecil (Gambar 4), karena nilai PGA di Sв juga kecil. Di dearh Purwoharjo utara, diperoleh nilai PGA dalam orde 0,5. Nilai ini identik dengan daerah perbatasan Gerbosari dan Ngargosari. Kedua desa tersebut memiliki frekuensi kejadian longsor yang 
Tabel 2. Nilai PGA (g) di batuan dasar $\left(\mathrm{S}_{\mathrm{B}}\right)$ di daerah Kulonprogo bagian utara untuk berbagai skenario perhitungan. Data ini diekstrak dari Peta Sumber dan Bahaya Gempa 2017. Norm P10 adalah nilai rasio terhadap P10 dalam persen.

\begin{tabular}{clcc}
\hline Kode & \multicolumn{1}{c}{ Penjelasan Skenario } & $\begin{array}{c}\text { PGA(g) } \\
\text { di S }\end{array}$ & $\begin{array}{c}\text { Norm } \\
\text { P10 }\end{array}$ \\
\hline P01 & Probabilitas > 20\% dalam 10 tahun (50 th return period) & 0.075 & $9 \%$ \\
P02 & Probabilitas > 10\% dalam 10 tahun (100 th return period) & 0.175 & $22 \%$ \\
P03 & Probabilitas > 5\% dalam 10 tahun (200 th return period) & 0.225 & $28 \%$ \\
P04 & Probabilitas > 10\% dalam 50 tahun (500 th return period) & 0.275 & $34 \%$ \\
P05 & Probabilitas > 7\% dalam 75 tahun (1000 th return period) & 0.35 & $44 \%$ \\
P06 & Spektrum Respon 0.2 sec dengan redaman 5\% di SB in 75 tahun & 0.75 & $94 \%$ \\
P07 & Spektrum Respon 1 sec dengan redaman 5\% di SB in 75 tahun & 0.35 & $44 \%$ \\
P08 & Probabilitas > 2\% dalam 50 tahun (2500 th return period) & 0.6 & $75 \%$ \\
P09 & Spektrum Respon 0.2 sec dengan redaman 2\% di SB in 50 tahun & 1.2 & $150 \%$ \\
P10 & Probabilitas > 1\% dalam 100 tahun (10000 th return period) & 0.8 & $100 \%$ \\
\hline
\end{tabular}

cukup tinggi dan terliput dari media-media berita di setiap musim penghujan. Bulan Desember-Maret merupakan bulan-bulan musim hujan, ketika kejenuhan air di dalam tanah permukaan juga akan menambah potensi kejadian longsor, terutama di area yang bertopografi dan lapuk.

Sementara itu, skenario kedua, yaitu P07, merupakan skenario untuk respon spektrum sebesar 1 detik (Gambar 5), dengan redaman sebesar 5\% dalam kurun waktu 75 tahun. Nilai maksimum PGA sebesar 3,8 g diperoleh di daerah yang disebutkan sebelumnya, yaitu Purwoharjo bagian utara dan perbatasan Gerbosari dan Ngargosari. Nilai PGA terkecil, yakni kurang dari 1,2 g, berada pada perbatasan Gerbosari dan Sidoharjo, terutama bagian tengah yang menerus ke arah selatan menuju batas dengan Banjarsari.

Daerah-daerah tersebut diperkirakan berpotensi akan mengalami goncangan dengan
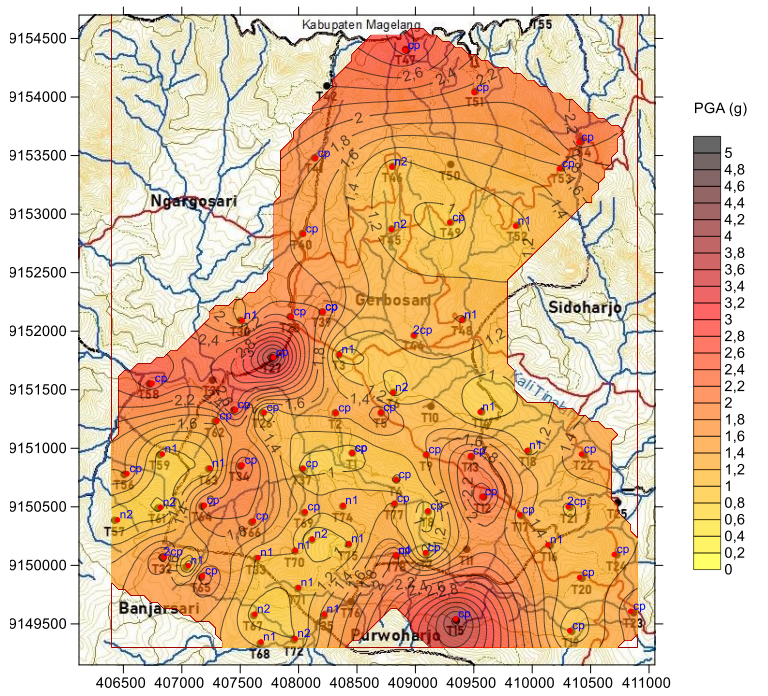

Gambar 5. Nilai PGA untuk skenario P07. Nilai maksimum PGA di permukaan tanah sekitar $3.8 \mathrm{~g}$ yang diperoleh pada puncak nilai maksimum sesuai Gambar 3. nilai tertampil dengan frekuensi sebesar $1 \mathrm{~Hz}$, frekuensi ini dimiliki sebagai frekuensi dasar dari sebagian besar bentuk rumah dan gedung yang dibangun. Nilai ini juga dapat diartikan bahwa daerah tersebut memiliki potensi memiliki getaran tanah yang sesuai dengan nilai PGA-nya apabila dikenakan pekerjaan yang menggunakan sumber getar, misalnya pekerjaan konstruksi pemasangan bor-pile (pakubumi), terutama yang berfrekuensi 1 $\mathrm{Hz}$.

Walaupun secara geoteknik rekayasa bangunan yang sesuai dengan skenario ini dapat dibuat, namun tentu saja membutuhkan biaya yang lebih besar dibandingkan dengan bangunan pada area dengan nilai PGA yang lebih kecil. Distribusi nilai PGA di daerah ini juga sangat diperlukan dalam upaya perhitungan secara empiris kekuatan geser tanah yang diperlukan untuk kajian geoteknik kebencanaan.

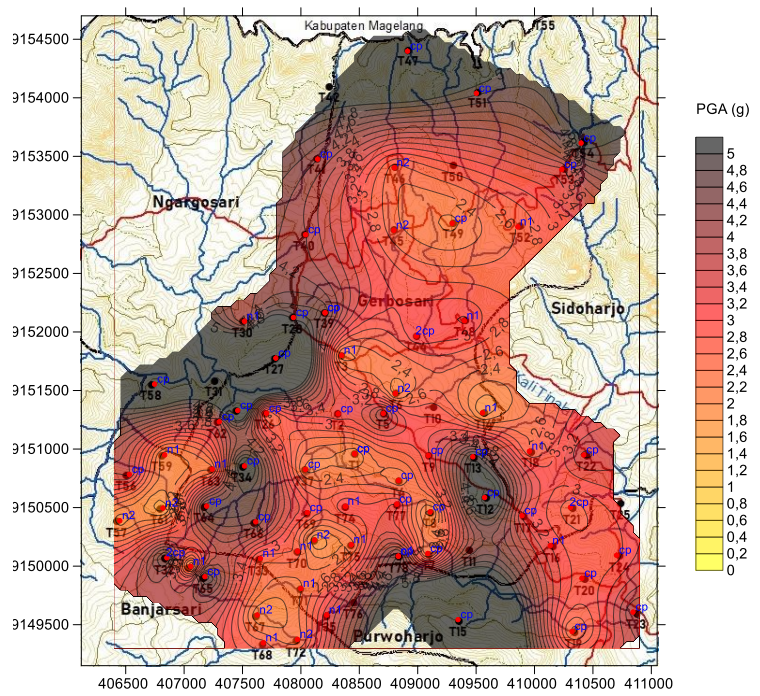

Gambar 6. Nilai PGA untuk skenario P10. Nilai maksimum PGA di permukaan tanah sekitar $5 \mathrm{~g}$ yang diperoleh pada puncak nilai maksimum sesuai Gambar 3. 
Pada skenario terberat, yaitu skenario P10, dimana nilai PGA lebih dari 5 g, didapatkan hampir diseluruh area, terutama area seputar Gerbosari dan perbatasan dengan desa-desa di sekitarnya. Nilai PGA dipermukaan sebesar ini sangat berpotensi merusak dan memberikan gaya horisontal ekstra yang besar pada model longsor. Gaya ini juga akan memberikan pengaruh yang besar jika ditambah dengan kandungan/kejenuhan air yang cukup besar di dalam tanah, geomorfologi yang berupa perbukitan, serta lapisan tanah hasil lapukan batuan yang cukup masif.

Skenario ini dipergunakan untuk periode ulang yang sangat panjang, hingga 10.000 tahun, dan apabila ingin dikaji secara empirik, nilai PGA pada skenario ini dapat dihitung untuk mendapatkan kondisi bangunan/struktur tanah yang aman hingga periode ulang tersebut.

\section{Kesimpulan}

Berdasar kajian dan perhitungan nilai amplifikasi, dan PGA baik di SB maupun di permukaan, diperoleh bahwa amplifikasi yang didapatkan dari HVSR menunjukkan semua bernilai lebih dari 1, yang mengindikasikan terdapat lapisan sedimen lapukan [11] di seluruh bagian daerah penelitian. Nilai PGA untuk skenario terendah di permukaan maksimum adalah 0,8 g yang cukup kecil dari sisi geoteknik. Nilai ini hanya muncul pada sisi barat dan tenggara di Gerbosari, dimana lokasi tersebut dilaporkan sering terjadi kejadian longsor $[5,14]$. Untuk skenario terberat, diperoleh PGA lebih dari $5 \mathrm{~g}$ di seputar Gerbosari dan berbatasan dengan desa-desa sekitarnya. Secara umum, kajian ini bermanfaat sebagai data masukan empiris, untuk kajian geoteknik, banjir bandang, dan longsor.

\section{Ucapan Terima Kasih}

Tulisan ini merupakan bagian dari hibah Penelitian Departemen Fisika, FMIPA, Universitas Gadjah Mada tahun 2020 dengan no kontrak 132/J01.1.28/PL.06.02/2020 tertanggal 2 April 2020. Penulis mengucapkan terimakasih kepada: BPBD Kulonprogo atas diskusi potensi longsor di wilayah penelitian serta fasilitas akomodasi. Lab Geofisika FMIPA atas persewaan instrumen Seismometer Lennartz dan Data Logger DAQ, serta reviewer anonymous atas review dan koreksiannya.

\section{Daftar Pustaka}

[1] USGS, Landslide Types and Processes, Highway Research Board Special Report, (July), pp.1-4, 2004.

[2] Rata-Rata Curah Hujan dan Hari Hujan Menurut Kecamatan Per Bulan di Kabupaten Kulon Progo, 2017,

[3] Westen, C. Van, Introduction to landslides Part 1 : Types and causes, Dont Use, 5pp.34, 2007.

[4] Abidin, M. H. Z., Saad, R., Ahmad, F., Wijeyesekera, D. C., and Baharuddin, M. F. T., Seismic refraction investigation on near surface landslides at the kundasang area in sabah, Malaysia, Procedia Engineering, 50(Icasce), pp.516-531, 2012.

[5] Anonim Bencana Tanah Longsor dan Banjir di Kecamatan Samigaluh. Website Kecamatan Samigaluh, Laporan. (2016).

[6] Highland, L. M. and Bobrowsky, P., The Landslide Handbook - A guide to under-standing landslides, US Geological Survey Circular, (1325), pp.1-147, 2008.

[7] Pilz, M., Parolai, S., Bindi, D., Saponaro, A., and Abdybachaev, U., Combining Seismic Noise Techniques for Landslide Characterization, Pure and Applied Geophysics, 171(8), pp.1729-1745, 2014.

[8] Mainsant, G., Larose, E., Brnnimann, C., Jongmans, D., Michoud, C. , and Jaboyedoff, M., Ambient seismic noise monitoring of a clay landslide: Toward failure prediction, Journal of Geophysical Research: Earth Surface, 117(1), pp.1-12, 2012.

[9] Bell, R., Kruse, J.-E., Garcia, A., Glade, T., and Hördt, A., Subsurface investigations of landslides using geophysical methods: geoelectrical applications in the Swabian Alb (Germany), Geographica Helvetica, 61(3), pp.201-208, 2006.

[10] Hartantyo, E., Brotopuspito, K. S., Sismanto, and Waluyo In Predicting the liquefaction phenomena from shear velocity profiling: Empirical approach to $6.3 \mathrm{Mw}$, May 2006 Yogyakarta earthquake, 2015.

[11] Mucciarelli, M. and Gallipoli, M. R., The Hvsr Technique From Microtremor To Strong Motion: Empirical and Statistical Considerations, 13th World conference on earthquake engineering, (45), pp.9, 2004.

[12] Á S. S. B., Ȧ M. M., and Bं M. P. H., Harmonic Response Analysis of Multi-Storey Building, Inpressco, 4(4), pp.2387-2391, 2014. 
POSITRON Vol. 10, No. 2 (2020), Hal. 148-154

[13] Chik, T. N. T., Zakaria, M. F., Remali, M. A., and Yusoff, N. A., Vibration Response of Multi Storey Building Using Finite Element Modelling, IOP Conference Series: Materials Science and Engineering, 136(1), 2016.
[14] Kronologi Tanah Longsor di Samigaluh Menurut Pemilik Rumah, jogja.tribunnews. com/2020/02/16/kronologi-tanah-longsordi-samigaluh-menurut-pemilik-rumah (accessed Dec. 24, 2020). 